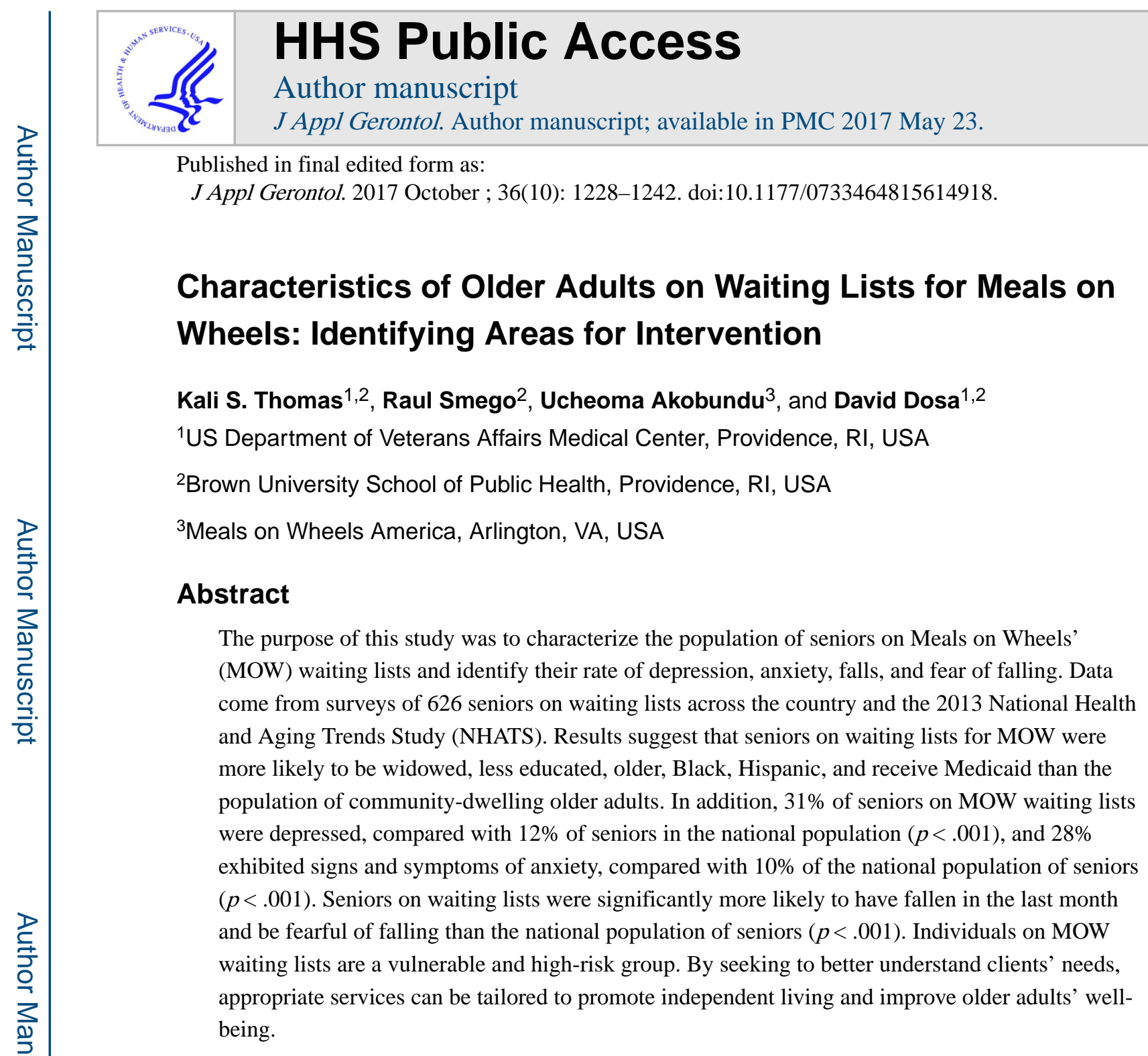

Keywords

home-delivered meals; depression; falls; homebound

\title{
Introduction
}

Home-delivered meals programs have been successful in reaching many older adults throughout the United States and have become a significant part of the national service strategy intended to support older adults in their own homes. Programs are generally popular

\footnotetext{
Reprints and permissions: sagepub.com/journalsPermissions.nav

Corresponding Author: Kali S. Thomas, Brown University, Box G-S121(6), Providence, RI 02912, USA., Kali_Thomas@ brown.edu. Authors' Note

This research has received approval from the Brown University Institutional Review Board (No. 1403001008). The views expressed in this article are those of the authors and do not necessarily reflect the position or policy of the Department of Veterans Affairs or the United States government.
}

Declaration of Conflicting Interests

The authors declared no potential conflicts of interest with respect to the research, authorship, and/or publication of this article. 
with consumers and seen as beneficial in helping them to meet their basic food needs often allowing individuals to age in place (Frongillo, Isaacman, Horan, Wethington, \& Pillemer, 2010; Sahyoun \& Vaudin, 2014; Zhu \& An, 2013). Previous research has demonstrated a relationship between state spending on home-delivered meals and the ability to keep older adults with low-care needs out of more costly care options such as nursing homes (Thomas $\&$ Mor, 2012). Research has also demonstrated that states that have increased their capacity in providing home-delivered meals also have recognized increased Medicaid savings by decreasing the proportion of low-care nursing home residents dually eligible for Medicaid and Medicare (Thomas \& Mor, 2013). Beyond providing financial savings to states, homedelivered meals are believed to improve the quality of life of older adults: The meals improve food and nutrient intake, reduce food insecurity, and may help increase older adults' independence while encouraging autonomy (Sahyoun \& Vaudin, 2014; Zhu \& An, 2013).

Despite the beneficial effects of the home-delivered meals program, funding for these services often fail to keep up with increased demand (Kamp, Wellman, \& Russell, 2010). During a time with decreases and stagnation in federal and state funding for the care of older adults, and an accompanying increase in the demand for at-home services, many programs have experienced a growth in their waiting lists for home-delivered meals. In 2013, Meals on Wheels America (formerly the Meals on Wheels Association of America) conducted a survey to understand the impact of Congressional sequestration on its members. Among the findings, survey respondents revealed that more than $70 \%$ were planning to establish a waitlist for services or add to previously existing waiting lists (Meals on Wheels America, 2013). On average, those programs forced to add to their waiting lists experienced an increase of 58 seniors (Meals on Wheels America, 2013).

The information submitted on the State Program Reports to the Administration for Community Living (ACL) and collected during the National Survey of Older Americans Act Participants gives us a general understanding of the needs and characteristics of individuals who receive services from the home-delivered meals program. In addition, a study of individuals on waiting lists for home-delivered meals in one state, Georgia, provides a bleak picture of their unmet nutritional need (Lee, Sinnett, Bengle, Johnson, \& Brown, 2011).

However, little is known about the characteristics and needs of individuals who are placed on growing waiting lists across the country. Therefore, the purpose of this study was to characterize the population of older adults on waiting lists for home-delivered meals, compare their non-nutrition-related needs with the population of older adults, and identify areas where they might be served through other public health interventions while they continue to wait for service.

\section{Design and Method}

\section{Study Samples}

Data come from the More Than a Meal project conducted by Meals on Wheels America with funding from AARP Foundation. As part of this project, a convenience sample of eight sites across the United States interviewed 626 individuals on waiting lists for homedelivered meals. The sites were selected based on survey responses to a Meals on Wheels America survey assessing the effects of the federal budget sequester on their programs and 
conducted in September to October 2013. The eight sites chosen all had average waitlist times of three or more months. Three sites were located in Texas and the rest were in Florida, Georgia, North Carolina, New Jersey, and Rhode Island. In total, 626 older adults agreed to participate in the study. Participants were randomly selected for participation by Meals on Wheels (MOW) program sites and interviewed by MOW program staff. Interviewer notes indicated that 17 individuals exhibited signs and symptoms of dementia. For individuals who were deemed to have cognitive or health impairments that made responding to questions difficult, a proxy interview or an interview with assistance from family/caregivers was conducted ( $<4 \%$ of all cases). The survey was conducted in person, in the participants' homes following their written consent to participate and took place between the winter of 2013 and spring of 2014.

To benchmark the characteristics and needs of the sample of individuals on waiting lists for home-delivered meals against a representative national population of older adults, we utilized publicly available data from the National Health and Aging Trends Study (NHATS; Kasper \& Freedman, 2014). The NHATS is sponsored by the National Institute on Aging (grant number NIA U01AG032947) through a cooperative agreement with the Johns Hopkins Bloomberg School of Public Health. Using a stratified, multistage sampling design, NHATS gathered information from a nationally representative sample of more than 8,000 Medicare beneficiaries aged 65 and older beginning in 2011 (response rate $=71 \%$ ) to investigate multiple aspects of functioning in older adults. Detailed descriptions of the methods and measures used in the NHATS have previously been published (Kasper \& Feedman, 2015). We used data from Round 3 of the study, which took place in 2013 (Johns Hopkins Bloomberg School of Public Health, n.d.), to provide a benchmark for which to compare our sample of homebound older adults on waiting lists for home-delivered meals. We excluded individuals in residential care facilities to maintain consistency with the MOW waiting list sample; therefore, our final NHATS sample consisted of 4,508 survey respondents representing 29,869,432 individuals. Analytic weights that take into account differential probabilities of selection and non-response were used to allow for generalization to the Medicare population aged 67 and older in 2013.

\section{Variables}

Conditions and characteristics of the MOW waiting list sample were selected with a focus on elements that might be amenable to intervention. The goal was to identify participants' non-nutrition-related needs that might be established during the MOW intake interview and be served through referral to other programming. We utilized questions that were available in both the NHATS data and in the survey of participants on waiting lists for MOW to make comparisons. Specifically, we investigated the rate of falls, fear of falling, whether this fear limited activities, as well as two mental health conditions: anxiety and depression.

Depression-Depression was measured using the Patient Health Questionnaire 2-item (PHQ-2) depression screener that has been validated and used in other studies (Kroenke, Spitzer, \& Williams, 2003; Löwe, Kroenke, \& Gräfe, 2005). This instrument comprised the following two items: "Over the last month, how often have you had little interest or pleasure in doing things?" and "Over the last month, how often have you felt down, depressed, or 
hopeless?" Response options were (a) not at all, (b) several days, (c) more than half the days, or (d) nearly every day. Items were summed and a score greater than or equal to three was used to signal that individuals screened positive for depression.

Anxiety-To evaluate anxiety, we used the Generalized Anxiety Disorder 2-item measure (GAD-2), developed as a screening test to detect anxiety disorders (Kroenke, Spitzer, Williams, Monahan, \& Löwe, 2007). The items included, "Over the last month, how often have you felt nervous, anxious, or on edge?" and "Over the last month, how often have you been unable to stop or control worrying?" with the following response options: (a) not at all, (b) several days, (c) more than half the days, or (d) nearly every day. Items were summed and a score of greater than or equal to three denoted a screening cutpoint for clinically significant anxiety (Kroenke, Spitzer, Williams, \& Löwe, 2010).

Fall-related items-Several questions about falling came from the NHATS and were included in the interviews, with "yes/no" response options. The definition used for falling that prefaced the questions was "By falling down, we mean any fall, slip, or trip in which you lose your balance and land on the floor or ground or at a lower level." This wording mirrors the definition used in the Women's Health and Aging Study (Guralnik, Fried, Simonsick, Kasper, \& Lafferty, 1995). Participants were asked whether or not they had fallen in the last month. To elicit fear of falling, participants were asked, "In the last month, did you worry about falling down?" If respondents answered yes, the follow-up question was asked: "Did this fear limit your activities?"

\section{Analysis}

We report the unweighted frequency of responses for the waiting list sample and the weighted frequency of responses for the NHATS sample. The NHATS responses were weighted to account for non-response and differential probabilities of selection among subgroups (e.g., the NHATS oversampled Blacks and individuals in the oldest age groups). Variance estimates were calculated using a Taylor series linearization that incorporated the complex sample design of the survey. Because both groups were asked the same series of questions to assess their demographics, mental health, rates of falls, and fear of falling, we wanted to compare the distribution of these responses between the sample of older adults on waiting lists for MOW and the population of community-dwelling older adults and determine whether their differences were statistically significant. To do this, we tested for statistically significant differences in the unweighted responses to each item, between groups, using chi-square tests. The resulting chi-square and significance values indicated whether the differences between groups were the result of chance or true differences between groups. The data analysis received expedited review and approval from the Brown University Institutional Review Board.

\section{Results}

Demographic characteristics of the sample of older adults on waiting lists for homedelivered meals and the weighted distribution of the NHATS sample are presented in Table 1. Participants on waiting lists for home-delivered meals were significantly more likely to 
have members from the oldest old age group than the population of community-dwelling older adults (19\% vs. $14 \%$ above the age of 85 , respectively). In addition, participants on waiting lists were also more likely to be Black (33\% vs. $8 \%$ ), Hispanic (12\% vs. $7 \%$ ), and to receive Medicaid benefits ( $32 \%$ vs. $12 \%$ ) than the population of community-dwelling older adults.

When examining mental health, $31 \%$ of the sample on waiting lists for home-delivered meals screened positive for depression using the PHQ-2, compared with $12 \%$ of seniors in the national population $\left(\chi^{2}=119.5, p<.001\right.$; Figure 1). In addition, $28 \%$ of seniors in the sample on waiting lists exhibited signs and symptoms of GAD using the GAD-2, compared with $10 \%$ in the national population of older adults $\left(\chi^{2}=124.5, p<.001\right)$.

Finally, when examining rates of falls, we found that individuals on waiting lists for homedelivered meals were significantly more likely to have reported a fall in the last month than the national population of older adults $\left(\chi^{2}=118.2, p<.001\right.$; Table 2$)$. Among those who had fallen in the sample of individuals on waiting lists, the mean number of falls reported in the past month per person was 2.2 falls ranging from 2 to 20 reported falls. In addition to having fallen, a statistically significant higher proportion of individuals on waiting lists reported being fearful of falling $\left(\chi^{2}=165.9, p<.001\right)$ and that those fears were more likely to limit their activities than the national population of older adults $\left(\chi^{2}=190.8, p<.001\right)$.

\section{Discussion}

Results from our study suggest that individuals on waiting lists for MOW are a vulnerable and high-risk group. In particular, individuals on waiting lists for MOW have more mental health needs and are at increased risk of falling compared with their counterparts of community-dwelling older adults. Home-delivered meals are often the first in-home service that older adults receive; and, increasing numbers of older adults are requesting these services and are assigned to growing waiting lists. Therefore, by incorporating questions that screen for fall risks and mental health issues at program intake, it is possible that appropriate services can be tailored to promote independent living and improve older adults' well-being, regardless of whether or not they immediately begin receiving home-delivered meals.

While previous studies have documented rates of depression and anxiety among older adults currently receiving in-home aging services, this is one of the first studies to examine the rates of depression and anxiety among individuals on waiting lists for these services. Research with clients receiving in-home aging services suggests that anywhere from $12 \%$ (Gum et al., 2009; Sirey et al., 2008) to almost one third of homebound older adults receiving services had clinically significant levels of depression (Charlson et al., 2008; Richardson et al., 2012) while other work has suggested that approximately $42 \%$ of homebound older adults receiving aging services exhibited symptoms of depression or anxiety (Simning et al., 2010). Our study, alongside others, confirms it is important that we integrate mental health screening for both depression and anxiety into the initial assessment to determine eligibility for services as well as assessments conducted for enrollment in services. This will ensure that homebound older adults who exhibit signs and symptoms of mental health problems are identified and referred to receive quality mental health care 
regardless of whether or not they have begun receiving in-home aging services. However, we recognize that screening and referral are not enough. Given the prevalence of these conditions and the real-world constraints of accessing clinic-based psychotherapy for this homebound population (e.g., stigma, lack of transportation, and burden of co-pay), there is a need for increased availability and funding for evidence-based in-home therapy programs accessible to low-income homebound older adults.

In a survey conducted among home-delivered meals providers, only $12 \%$ of programs reported assessing their clients for depression as part of its standard assessment protocol (Choi, Lee, \& Goldstein, 2011). Yet, more than half of the home-delivered meals providers surveyed in that study reported that they wanted to include mental health screening into their array of services. Our study demonstrated that it is feasible to train assessors to deliver these mental health screeners and to integrate mental health screening into intake assessments required for MOW program participation. In addition to including screening questions into the intake assessment, we advocate for targeted training and skill development to support the ability of MOW staff and volunteers to facilitate not only mental health screening but also referral to mental health services for homebound older adults in need, particularly those who are unable to be served immediately by MOW programs.

The incidence and prevalence of older adults who fall and suffer serious injuries is a public health problem in the United States and around the world (World Health Organization, 2007). In the United States, almost 2.5 million non-fatal falls among older adults were treated in emergency departments in 2013 (National Center for Injury Prevention and Control), and in the past 10 years, more than 200,000 older Americans' deaths were attributable to a fall-related event (Shumway-Cook et al., 2009). Our data suggest that individuals who are in need of home-delivered meals are at increased risk of falls compared with the general population of older adults. In addition, individuals in our sample of seniors on waiting lists for home-delivered meals were more fearful of falling than the general population of community-dwelling older adults. There is a growing body of evidence that suggests that fear of falling may constitute an important risk factor for restriction of activity that can lead to greater disability, decreased social activity, and ultimately reduced ability to live independently (Cumming, Salkeld, Thomas, \& Szonyi, 2000; Martin, Hart, Spector, Doyle, \& Harari, 2005; Suzuki, Ohyama, Yamada, \& Kanamori, 2002; Vellas, Wayne, Romero, Baumgartner, \& Garry, 1997; Yardley \& Smith, 2002). In addition, falling has been shown to be a risk factor for developing fear of falling with a reported $21 \%$ to $39 \%$ of patients without fear of falling at baseline developed fear of falling after a fall during followup (Friedman, Munoz, West, Rubin, \& Fried, 2002; Martin et al., 2005). Therefore, it is important to identify individuals who are at risk of falling and are fearful of falling to provide interventions that reduce the likelihood of falls, fear of falling, and subsequent decline. Given that the prevalence of falls and fear of falling is much greater in the sample of individuals on waiting lists for home-delivered meals, this warrants increased attention to measuring, identifying, and implementing fall-prevention interventions among this group.

The Administration on Aging's Older Americans Act Title III-D program provides funding for administration of evidence-based programming, including a number of programs for reducing fall risk and fear of falling as well as reducing the severity of depressive symptoms 
and improving mood. Many of these programs can be offered in the participants' homes (Bartsch \& Rodgers, 2009; Campbell et al., 2005; Choi, Sirey, \& Bruce, 2013; Ciechanowski et al., 2004; Cumming et al., 1999; Davison, Bond, Dawson, Steen, \& Kenny, 2005;

Robertson \& Gillespie, 2013; Sirey et al., 2013). Including questions that screen for fall risk and mental health issues during intake evaluations for home-delivered meals programs would allow for Local Area Agencies on Aging and State Units on Aging to better understand the needs of their clients. Armed with this awareness, the Aging Network could target the implementation and deployment of these evidence-based Title III-D programs to meet the greatest needs in their community. By reducing fragmented in-home service delivery and implementing a holistic approach to caring for home-bound older adults, we could potentially see an increase in positive outcomes, namely, the ability of these older adults to remain in the community.

\section{Limitations}

There are some limitations to this study worth noting. We were unable to make direct comparisons between individuals on waiting lists for home-delivered meals and older adults who met similar criteria who were not on waiting lists for home-delivered meals. This largely stems from the variability in definitions and criteria for eligibility for MOW homedelivered meals program. For example, the definition of "homebound" is not a hard metric and can vary by site and person. Also, some programs have more strict criteria to be considered eligible for service. Therefore, it was not possible to create a similar group in the NHATS sample without consistently defined metrics available to identify and establish a comparable group. We also acknowledge that there were differences in the rigorous manner in which NHATS data were sampled and collected and the convenience sample of those on MOW waiting lists. It was not our intent to utilize NHATS data as a hard comparison against MOW collected data. Rather, our goal was to provide a framework or benchmark for comparison of the waiting list cohort against a community-dwelling population. It should also be noted that because this was a convenience sample of individuals on MOW waiting lists, that they may not be representative of the national population on waiting lists for home-delivered meals.

It is important to point out the differences in the age eligibility in each of the two samples. NHATS was designed to represent the sample of older Medicare beneficiaries and began in 2011. Therefore, the analytic weights estimate the characteristics of people aged 65 and older in 2011 (Round 1), 66 and older in 2012 (Round 2), and 67 and older in 2013 (Round 3 ). While the NHATS data represents individuals above the age of 67 , the sample of older adults on waiting lists for MOW includes homebound individuals below the age of 67 ( $n=$ $141,23 \%)$. Sensitivity analyses suggested that there were no statistically significant differences in rate of falls, fear of falling, depression, or anxiety between individuals younger and older than 67 in the MOW waiting lists sample, and therefore, we saw no need to limit our analysis to individuals on waiting lists above the age of 67 . We hypothesize that were we to have data available on younger individuals in the community population with similar ages to those in the sample on waiting lists for home-delivered meals, that the differences in the rates of falls, fear of falling, and mental health problems would be even greater. 
Finally, it is important to point out that all but one site reported that they prioritized their waiting lists so that those most in need would receive services first. As such, we believe that the characteristics of individuals in the waiting list cohort may have been modest in comparison with the population currently receiving home-delivered meals. Future research should investigate the mental health characteristics and likelihood of falling among individuals who are determined to be most at need and already enrolled in the program to more fully understand the magnitude of these issues among individuals who seek out assistance from home-delivered meals programs.

\section{Conclusion}

This is among the first studies to examine the non-nutrition-related characteristics of older adults who are affected by growing waiting lists for home-delivered meals. Results from this study suggest that older adults on waiting lists for home-delivered meals represent a vulnerable population of older adults who are at increased risk for mental health issues and falls. We believe that by highlighting the needs of this population, proper interventions can be developed and deployed in conjunction with other in-home services, such as homedelivered meals, to improve the health and well-being of homebound older adults.

\section{Acknowledgments}

Funding

The authors disclosed receipt of the following financial support for the research, authorship, and/or publication of this article: This research project has been sponsored by Meals on Wheels America and has been made possible by a grant from AARP Foundation.

\section{Biographies}

Kali S. Thomas is a Research Health Science Specialist at the Providence VA Medical Center's Center of Innovation for Long-Term Services and Supports and an assistant professor (research) of Health Services, Policy and Practice at Brown University. Her research focuses on quality of care in long-term care and the role of home- and communitybased services in preventing or postponing nursing home placement.

Raul Smego is a graduate of the masters of public health program at Brown University, Providence Rhode Island. He received his BA in biology from Drew University in 2013. His research interests are in the field of environmental health, specifically organic pollutants and endocrine disruption.

Ucheoma Akobundu is the director of project management and impact at Meals on Wheels America. She holds a BS in biology (State University of New York-Albany), an MS in nutrition with a concentration in public health (University of Massachusetts-Amherst), a $\mathrm{PhD}$ in nutrition (University of Maryland-College Park), and has also trained to become a registered dietitian.

David Dosa is a health services researcher and practicing geriatrician with dual appointments with the Department of Primary Care at the Providence VA Medical Center 
and the Division of Geriatrics at Rhode Island Hospital. He jointly conducts his research through Brown University's Center for Gerontology and the Providence VA Medical Center of Innovation for Long-Term Services and Supports.

\section{References}

Bartsch DA, Rodgers VK. Senior Reach outcomes in comparison with the Spokane Gatekeeper program. Care Management Journals. 2009; 10(3):82-88. [PubMed: 19772205]

Campbell AJ, Robertson MC, La Grow SJ, Kerse NM, Sanderson GF, Jacobs RJ. Randomised controlled trial of prevention of falls in people aged $\geq 75$ with severe visual impairment: The VIP trial. British Medical Journal. 2005; 331:817-825. [PubMed: 16183652]

Charlson ME, Peterson JC, Syat BL, Briggs WM, Kline R, Dodd M, ... Dionne W. Outcomes of community-based social service interventions in homebound elders. International Journal of Geriatric Psychiatry. 2008; 23:427-432. [PubMed: 17918183]

Choi NG, Lee A, Goldstein M. Meals on wheels: Exploring potential for and barriers to integrating depression intervention for homebound older adults. Home Health Care Services Quarterly. 2011; 30:214-230. [PubMed: 22106903]

Choi NG, Sirey JA, Bruce ML. Depression in homebound older adults: Recent advances in screening and psychosocial interventions. Current Translational Geriatrics and Gerontology Reports. 2013; 2:16-23.

Ciechanowski P, Wagner E, Schmaling K, Schwartz S, Williams B, Diehr P, ... LoGerfo J. Community-integrated home-based depression treatment in older adults: A randomized controlled trial. Journal of the American Medical Association. 2004; 291:1569-1577. [PubMed: 15069044]

Cumming RG, Salkeld G, Thomas M, Szonyi G. Prospective study of the impact of fear of falling on activities of daily living, SF-36 scores, and nursing home admission. The Journals of Gerontology, Series A: Biological Sciences \& Medical Sciences. 2000; 55(5):M299-M305.

Cumming RG, Thomas M, Szonyi M, Salkeld G, O’Neill E, Westburg C, Frampton G. Home visits by an occupational therapist for assessment and modification of environmental hazards: A randomized trial of falls prevention. Journal of the American Geriatrics Society. 1999; 47:1397-1402. [PubMed: 10591231]

Davison J, Bond J, Dawson P, Steen IN, Kenny RA. Patients with recurrent falls attending accident and emergency benefit from multifactorial intervention: A randomised controlled trial. Age and Ageing. 2005; 34:162-168. [PubMed: 15716246]

Friedman SM, Munoz B, West SK, Rubin GS, Fried LP. Falls and fear of falling: Which comes first? A longitudinal prediction model suggests strategies for primary and secondary prevention. Journal of the American Geriatrics Society. 2002; 50:1329-1335. [PubMed: 12164987]

Frongillo EA, Isaacman TD, Horan CM, Wethington E, Pillemer K. Adequacy of and satisfaction with delivery and use of home-delivered meals. Journal of Nutrition for the Elderly. 2010; 29:211-226. DOI: 10.1080/01639361003772525 [PubMed: 20473813]

Gum AM, Petkus A, McDougal SJ, Present M, King-Kallimanis B, Schonfeld L. Behavioral health needs and problem recognition by older adults receiving home-based aging services. International Journal of Geriatric Psychiatry. 2009; 24:400-408. DOI: 10.1002/gps.2135 [PubMed: 18836987]

Guralnik, JM.Fried, LP.Simonsick, EM.Kasper, JD., Lafferty, ME., editors. The Women's Health and Aging Study: Health and social characteristics of older women with disability. Bethesda, MD: National Institute on Aging; 1995.

Johns Hopkins Bloomberg School of Public Health. NHATS public use data (Round 3). n.d. Available from www.nhats.org

Kamp BJ, Wellman NS, Russell C. Position of the American Dietetic Association, American society for nutrition, and society for nutrition education: Food and nutrition programs for communityresiding older adults. Journal of Nutrition Education and Behavior. 2010; 42:72-82. DOI: 10.1016/ j.jneb.2009.12.001 [PubMed: 20219721]

Kasper, JD., Feedman, VA. National Health and Aging Trends Study (NHATS) User Guide: Rounds 1, 2 \& 3 final release. Baltimore, MD: Johns Hopkins University School of Public Health; 2015. 
Kasper JD, Freedman VA. Findings from the 1st round of the National Health and Aging Trends Study (NHATS): Introduction to a Special Issue. The Journals of Gerontology, Series B: Psychological Sciences \& Social Sciences. 2014; 69:S1-S7. DOI: 10.1093/geronb/gbu125

Kroenke K, Spitzer RL, Williams JB. The Patient Health Questionnaire-2: Validity of a two-item depression screener. Medical Care. 2003; 41:1284-1292. [PubMed: 14583691]

Kroenke K, Spitzer RL, Williams JB, Löwe B. The Patient Health Questionnaire Somatic, Anxiety, and Depressive Symptom Scales: A systematic review. General Hospital Psychiatry. 2010; 32:345359. [PubMed: 20633738]

Kroenke K, Spitzer RL, Williams JB, Monahan PO, Löwe B. Anxiety disorders in primary care: Prevalence, impairment, comorbidity, and detection. Annals of Internal Medicine. 2007; 146:317325. [PubMed: 17339617]

Lee JS, Sinnett S, Bengle R, Johnson MA, Brown A. Unmet needs for the Older Americans Act Nutrition Program. Journal of Applied Gerontology. 2011; 30:587-606. DOI: $10.1177 / 0733464810376512$

Löwe B, Kroenke K, Gräfe K. Detecting and monitoring depression with a two-item questionnaire (PHQ-2). Journal of Psychosomatic Research. 2005; 58:163-171. [PubMed: 15820844]

Martin FC, Hart D, Spector T, Doyle DV, Harari D. Fear of falling limiting activity in young-old women is associated with reduced functional mobility rather than psychological factors. Age and Ageing. 2005; 34:281-287. [PubMed: 15863412]

Meals on Wheels America. New survey details impact of sequester on Meals on Wheels Programs. 2013. [Press release]. Retrieved from www.mealsonwheel-samerica.org/docs/default-source/NewsAssets/june-2013-sequester-survey-announcement.pdf?sfvrsn=2

National Center for Injury Prevention and Control. Web-Based Injury Statistics Query and Reporting System (WISQARS). Atlanta, GA: Centers for Disease Control and Prevention; 2015.

Richardson TM, Friedman B, Podgorski C, Knox K, Fisher S, He H, Conwell Y. Depression and its correlates among older adults accessing aging services. American Journal of Geriatric Psychiatry. 2012; 20:346-354. [PubMed: 22434017]

Robertson MC, Gillespie LD. Fall prevention in community-dwelling older adults. Journal of the American Medical Association. 2013; 309:1406-1407. DOI: 10.1001/jama.2013.3130 [PubMed: 23549586]

Sahyoun NR, Vaudin A. Home-delivered meals and nutrition status among older adults. Nutrition in Clinical Practice. 2014; 29:459-465. [PubMed: 25030738]

Shumway-Cook A, Ciol MA, Hoffman J, Dudgeon BJ, Yorston K, Chan L. Falls in the Medicare population: Incidence, associated factors, and impact on health care. Physical Therapy. 2009; 89:324-332. [PubMed: 19228831]

Simning A, Richardson TM, Friedman B, Boyle LL, Podgorski C, Conwell Y. Mental distress and service utilization among help- seeking, community-dwelling older adults. International Psychogeriatrics. 2010; 22:739-749. [PubMed: 20478101]

Sirey JA, Bruce ML, Carpenter M, Booker D, Reid C, Newell K, Alexopoulos GS. Depressive symptoms and suicidal ideation among older adults receiving home delivered meals. International Journal of Geriatric Psychiatry. 2008; 23:1306-1311. [PubMed: 18615448]

Sirey JA, Greenfield A, DePasquale A, Weiss N, Marino P, Alexopoulos GS, Bruce ML. Improving engagement in mental health treatment for home meal recipients with depression. Journal of Clinical Interventions in Aging. 2013; 8:1305-1312. DOI: 10.2147/CIA.S49154 [PubMed: 24101866]

Suzuki M, Ohyama N, Yamada K, Kanamori M. The relationship between fear of falling, activities of daily living and quality of life among elderly individuals. Nursing \& Health Sciences. 2002; 4:155-161. [PubMed: 12406202]

Thomas KS, Mor V. The relationship between Older Americans Act title III state expenditures and prevalence of low-care nursing home residents. Health Services Research. 2012; 48:1215-1216. DOI: 10.1111/1475-6773.12015 [PubMed: 23205536]

Thomas KS, Mor V. Providing more home-delivered meals is one way to keep older adults with low care needs out of nursing homes. Health Affairs. 2013; 32:1796-1802. DOI: 10.1377/hlthaff. 2013.0390 [PubMed: 24101071] 
Vellas BJ, Wayne SJ, Romero LJ, Baumgartner RN, Garry PJ. Fear of falling and restriction of mobility in elderly fallers. Age and Ageing. 1997; 26:189-193. [PubMed: 9223714]

World Health Organization. WHO global report on falls prevention in older age. Geneva, Switzerland: Author; 2007.

Yardley L, Smith H. Prospective study of the relationship between feared consequences of falling and avoidance of activity in community-living older people. The Gerontologist. 2002; 42:17-23. [PubMed: 11815695]

Zhu H, An R. Impact of home-delivered meal programs on diet and nutrition among older adults: A review. Nutrition and Health. 2013; 22:89-103. DOI: 10.1177/0260106014537146 [PubMed: 24916974] 


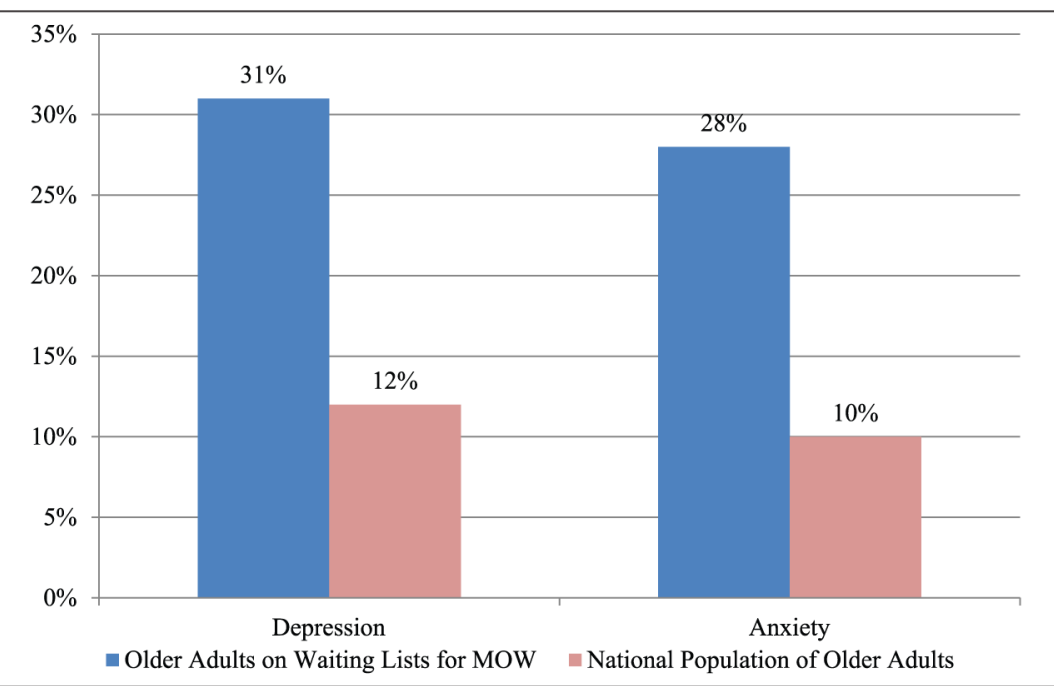

Figure 1.

Rates of depression and anxiety among older adults on waiting lists for MOW and the national population of community-dwelling older adults.

Note. Differences between groups significant at the $p<.001$ level. National population estimates are weighted. MOW $=$ Meals on Wheels. 


\section{Table 1}

Demographic Characteristics of the National Population of Community-Dwelling Older Adults and the Sample of Older Adults on Waiting Lists for MOW.

\begin{tabular}{lcc}
\hline & $\begin{array}{c}\text { National population of community- } \\
\text { dwelling older adults } \boldsymbol{n} \text { (weighted \%) }\end{array}$ & $\begin{array}{c}\text { Older adults on waiting lists for } \\
\text { MOW } \boldsymbol{n}(\boldsymbol{\%})\end{array}$ \\
\hline Marital status & & $149(24)$ \\
Married & $2,142(55)$ & $280(45)$ \\
Widowed & $1,578(28)$ & $93(15)$ \\
Age & & $178(28)$ \\
$<65$ & $\mathrm{n} / \mathrm{a}$ & $201(32)$ \\
$65-74$ & $1,537(48)$ & $153(25)$ \\
$75-84$ & $1,916(38)$ & $171(28)$ \\
$85+$ & $1,055(14)$ & $244(40)$ \\
Education & & $202(32)$ \\
Less than high school & $1,126(23)$ & $182(32)$ \\
High school diploma or General Educational & $1,198(27)$ & $369(60)$ \\
Development (GED) Certificate of High School & & $212(33)$ \\
Some college or higher & $1,846(50)$ & $75(12)$ \\
Race and ethnicity & & \\
White & $3,126(81)$ & \\
Black & $973(8)$ & \\
Hispanic or Latino & $259(7)$ & \\
Insurance & $648(12)$ & \\
Medicaid & & \\
\hline
\end{tabular}

Note. Differences between groups significant at the $p<.001$ level. MOW $=$ Meals on Wheels. 


\section{Table 2}

Rates of Falls and Worries About Falling Among the National Population of Older Adults and Older Adults on Waiting Lists for MOW.

\begin{tabular}{lcc}
\hline & $\begin{array}{c}\text { National population of community-dwelling older adults } \boldsymbol{n} \\
\text { (weighted \%) }\end{array}$ & Older adults on waiting lists for MOW $\boldsymbol{n}$ (\%) \\
\hline Fallen in past month & $517(10)$ & $171(27)$ \\
Worried about falling & $1,361(28)$ & $350(56)$ \\
Fear limited activities & $514(36)$ & $277(79)$ \\
\hline
\end{tabular}

Note. Differences between groups significant at the $p<.001$ level. MOW $=$ Meals on Wheels. 